\title{
Stabilizing high sulfur loading Li-S batteries by chemisorption of polysulfide on three-dimensional current collector
}

Xiwen Wang ${ }^{1,2}$, Tao Gao ${ }^{1}$, Fudong $\mathrm{Han}^{1}$, Zhaohui $\mathrm{Ma}^{1}$, Zhian Zhang ${ }^{2}$, Jie $\mathrm{Li}^{2}$ and Chunsheng Wang ${ }^{1, *}$

1. Department of Chemical and Biomolecular Engineering, University of Maryland, College Park, MD 20742, USA

2. School of Metallurgy and Environment, Central South University, Changsha, 410083, China

Abstract: The large volume change during cycles, extreme low electronic/ionic conductivity of sulfur and lithium sulfide, and high solubility of high-order polysulfide (PS) in electrolyte are three major barriers for practical applications of Li-S batteries. Current strategy to migrate these three issues is to physically and/or chemically encapsulate the sulfur into porous carbon host $(\mathrm{PCH})$, which is only suitable for a low S loading cathode. The large volume change during charge-discharge process especially in a thicker electrode with high areal S loading will detach the carbon/ $/ \mathrm{Li}_{2} \mathrm{~S}$ particles apart from each other, resulting in fast capacity decay. Although incorporation of large amount of S into 3D carbon paper (CP) can maintain the electrode integration, it cannot effectively immobilize soluble PS. In this work, we chemically bond the PS to both doped $\mathrm{PCH}$ and 3D doped $\mathrm{CP}$ current collector to suppress the shuttle reaction of PS, and also maintain the electronic/ionic connection during prolonged cycles. The $\mathrm{S}, \mathrm{N}$ doped $\mathrm{CP} /$ doped $\mathrm{PCH} / \mathrm{S}$ cathode with high areal sulfur loading of $9.0 \mathrm{mg} \mathrm{cm}^{-2}$ provide a high capacity of $1013 \mathrm{mAh} \mathrm{g}^{-1}$ with 
a slow capacity fading rate of $0.074 \%$ per cycle for 300 cycles, presenting one of the best cycling stability at the similar S loading reported to date. Moreover, systematic investigations demonstrated that chemical bonding of PS to CP current collector can more effectively enhance the cycling stability of high sulfur loading cathode, compared to the current method by chemical bonding of PS to PCH. This sulfur cathode by filling a large amount of S/C composites into functionalized CP matrix bring a new and promising direction to realization of high energy lithium-sulfur batteries.

Keywords: Lithium-sulfur batteries; High sulfur loading cathode; Chemical adsorption; Current Collector; Cycle life

\section{Introduction}

Lithium-sulfur (Li-S) batteries have been regarded as one of the most attractive candidates for next-generation energy storage system because of their high energy density of $2600 \mathrm{Wh} \mathrm{Kg}^{-1}$ and low cost.[1] However, three major challenges hinder the practical application of Li-S battery: 1) the insulating nature of sulfur and discharge products; 2) the large volume changes of sulfur during charge/discharge cycling; 3) the shuttle reaction between two electrodes due to the dissolution/diffusion of polysulfide (PS).[2] In recent years, extensive effort have been devoted to address these obstacle. The most successful method is to chemically bond the sulfur or PS onto various porous carbon hosts, enabling high specific capacity (>1300 $\mathrm{mAh} \mathrm{g}^{-1}$ ) and long cycling stability $(<0.1 \%$ capacity fading per cycle).[3] However, the low 
areal sulfur loading $\left(<2 \mathrm{mg} \mathrm{cm}^{-2}\right)$ in the most reported Li-S batteries cathode results in a low capacity per area, which is even lower than that of current lithium-ion batteries.[4] Therefore, the design of sulfur cathode with a high sulfur loading over 5 $\mathrm{mg} \mathrm{cm}{ }^{-2}$ is essential to the commercialization of Li-S batteries. Unfortunately, simply increasing the sulfur loading by slurry-coating more S/C composites on the flat aluminum foil cannot guarantee superior electrochemical performance of batteries. With increasing thickness of electrode, maintenance of the high ionic and electronic conductivity will become more challenged.[5,6] Moreover, the large volume change of sulfur $(>70 \%)$ during charge/discharge process gradually detach the carbon particles from particles and from current collector, deteriorating the electrode structure and then reducing the cycle life, especially at a high sulfur loading. Thus, S cathode with cross-linked three dimensional electronic conductive network is desired for achieving both high energy density and the long cycle life of Li-S battery.[7,8]

Carbon paper (CP) consisting of carbon fibers network has been used as the interlayer to suppress shuttle effect $[9,10]$ and the current collector of sulfur cathode which provide a high capacity over $1000 \mathrm{mAh} \mathrm{g}^{-1}$ even with a sulfur loading of 6.7 $\mathrm{mg} \mathrm{cm}{ }^{-2} .[11]$ However, these high sulfur loading cathodes using CP current collector still suffer a rapid capacity fading over long-term cycling, because the physical adsorption of high-order PS to carbon network is not sufficient to confine outward diffusion of PS, especially at a high PS concentration due to the high sulfur loading cathode. When sulfur loading are increased, the capacity of batteries degrade faster than that of a lower sulfur loading battery.[12] Although dual-layer CP design can 
extends the time for polysulfide diffusion out of sulfur cathode, it will reduce the volumetric energy density and cannot inhibit the lithium corrosion by the large amount of dissolved PS which terminates the high energy Li-S batteries' cycle life.[13] Introducing chemical interaction between carbon host and PS has been proven to effectively increase PS affinity of sulfur host materials.[14] Different heteroatom dopants on the carbon material such as oxygen[15], boron[16], nitrogen[17-21] and sulfur, nitrogen dual-dopant[22] were reported to absorb polysulfide and increase electronic conductivity of electrode. First-principles calculation and surface analysis further showed polar-polar interaction[23] and Lewis acid-base interaction[24] with PS are strong and stable. Therefore, utilizing the chemical adsorption of CP may significantly suppress the diffusion of PS and enhance overall performance of high energy Li-S cells.

Herein, we significantly stabilized cycle life of high-sulfur loading cathode by the chemisorption of PS to CP current collector and PCH through the hetero-atoms doping of $\mathrm{CP}$ and $\mathrm{PCH}$. The function groups with $\mathrm{O}, \mathrm{N}$ and $\mathrm{N} / \mathrm{S}$ have been grafted onto carbon paper, and their chemical bonding to polysulfide have been systemically investigated, as schematically depicted in Fig. 1. The modified CP/PCH/S cathodes with either low or high sulfur loading shows a much better cycling performance than that of pristine $\mathrm{CP} / \mathrm{PCH} / \mathrm{S}$ cathodes. In addition to physically trapping $\mathrm{PS}$ in $\mathrm{CP}$ and $\mathrm{PCH}$, extra chemisorption of PS on $\mathrm{CP}$ can more efficiently immobilize the PS compared to the chemisorption of PS to $\mathrm{PCH}$. In addition, the chemisorption of $\mathrm{CP}$ is also beneficial to retain the electronic contact in electrode even at a high $\mathrm{S}$ loading. The 
sulfur cathode with high sulfur loading of $9.0 \mathrm{mg} \mathrm{cm}^{-2}$ were achieved with the high initial capacity of $1013 \mathrm{mAh} \mathrm{g}^{-1}$ and stable cycling performance $(0.074 \%$ capacity fading per cycle). The results in our work not only highlight the crucial role of chemisorption of PS on CP current collector in achieving both high and stable electrochemical performance of sulfur cathode which has not been reported before, but also provides a new direction to commercialize the energy Li-S batteries with long cycle life.

\section{Experimental section}

\subsection{Materials Preparation}

The carbon papers (TGP-H-030, Fuel cell store, U.S) in this work consisting of $95 \mathrm{wt} \%$ carbon fibers and $5 \mathrm{wt} \%$ PTFE binder, show a thickness of $110 \mu \mathrm{m}$, porosity of $78 \%$, and electrical conductivity of $172 \mathrm{~S} \mathrm{~cm}^{-1}$, areal weight of $4.4 \mathrm{mg} \mathrm{cm}^{-2}$. An acid treatment were performed to functionalize $\mathrm{CP}$ with oxygen containing groups. Pristine CPs were cut into circular disks with a diameter of $0.95 \mathrm{~cm}$ and immersed in a mixture of concentrated $\mathrm{H}_{2} \mathrm{SO}_{4}$ and $\mathrm{HNO}_{3}$ in volume ratio of $3: 1$ at $60{ }^{\circ} \mathrm{C}$ for $1 \mathrm{~h}$. Acid-treated CPs were then washed by water and dried at $60^{\circ} \mathrm{C}$ for $24 \mathrm{~h}$.

As-prepared oxygenated CPs were used as precursor to synthesize N-doped CP and N, S co-doped CP. The oxygenated CPs was added into the urea or thiourea/ ammonium thiocyanate $(1: 1)$ solution with a mass ratio of $1: 30$. These mixture were transferred into Teflon-lined autoclave and heated at $180{ }^{\circ} \mathrm{C}$ for $12 \mathrm{~h}$. Then the autoclave was naturally cooled to room temperature and the collected modified CPs were washed and dried. 
$\mathrm{N}, \mathrm{S}$ co-doped CMK-3 carbon were synthesized by an ionic liquid coating followed by carbonization. Specifically, $100 \mu \mathrm{L}$ 1-Methyl-1-propylpiperidinium bis(trifluoromethanesulfonyl)imide ([PP13][TFSI]) were dropped into $50 \mathrm{mg}$ pristine CMK-3 mesoporous carbon and then shocked by vortex mixer. This mixture was heated at 180,240 , and $750{ }^{\circ} \mathrm{C}$ for 1,1 , and $2 \mathrm{~h}$ at a heating rate of $2{ }^{\circ} \mathrm{C} \min ^{-1}$, respectively in a quartz boat in argon for $\mathrm{N}, \mathrm{S}$ co-doping.

0.5 $\mathrm{M} \mathrm{Li}_{2} \mathrm{~S}_{6}$ solution were prepared by mixing lithium sulfide and sulfur (molar ratio=1:5) in 1,2-dimethyoxyethane (DME). The $50 \mathrm{mg}$ CMK-3 mesoporous carbon were added into $10 \mathrm{~mL} \mathrm{Li}_{2} \mathrm{~S}_{6}$ solution. To fabricate the $\mathrm{CP} / \mathrm{S}$ electrode, $11.1 \mu \mathrm{L}$ and $66.4 \mu \mathrm{L}$ polysulfide/carbon solutions were slowly dropped onto CPs disks and then dried in argon. Taking into account the weight of CP and CMK-3 carbon, the actual sulfur content in the whole electrodes with 1.5 and $9.0 \mathrm{mg} \mathrm{cm}^{-2}$ are $25 \mathrm{wt} \%$ and 65 $\mathrm{wt} \%$ as further confirmed by the TGA analysis (Fig. S1). Even if $65 \mathrm{wt} \%$ sulfur in the electrode, this sulfur content is still higher than the $36.3 \mathrm{wt} \%$ sulfur content in traditional slurry-coated thick sulfur $\left(5 \mathrm{mg} \mathrm{cm}^{-2}\right)$ electrodes using carbon black, binder and heavy aluminum foil current collector.[6]

\subsection{Material Characterizations}

The surface morphology of samples was investigated by scanning electron microscope (SEM, Hitachi Su-70, Japan). Raman measurements were performed on a Horiba Jobin Yvon Labram Aramis using a $532 \mathrm{~nm}$ diode-pumped solid-state laser. Surface groups and bond of samples were characterized via X-ray photoelectron spectroscopy (XPS, Kratos Axis 165, USA) using monochromatic Al Ka radiation at 
room temperature. All reported binding energy values are calibrated to the $\mathrm{C} 1 \mathrm{~s}$ peak at $284.8 \mathrm{eV}$. XPS data fittings were performed using Casa-XPS program with Gaussiane-Lorentzian functions after subtraction of a Shirley background. The fitting errors of XPS test results using this method are within $1 \%$.

All electrochemical studies were performed using 2025 coin cells which consist of a lithium metal anode, a Celgard 3501 separator and a cathode. The cells were assembled in a argon-filled glove box and $1 \mathrm{M}$ bis(trifluoromethane) sulfonamide lithium salt (LiTFSI, Sigma Aldrich) in a mixture of 1, 3-dioxolane (DOL) and 1,2-dimethoxyethane (DME) (v/v, 1:1) with $1 \mathrm{wt} \% \mathrm{LiNO}_{3}$ was used as the electrolyte. Both the specific capacities and current densities were calculated on the basis of the mass of sulfur. The galvanostatic charge/discharge tests were carried out in potential range from 1.7 to $2.7 \mathrm{~V}$ with a LAND CT2001A battery-testing system. The cells were first discharged to $1.7 \mathrm{~V}$ and then the cycle number was counted. All the electrochemical tests were conducted at room temperature. The EIS were measured on PARSTAT 2273 electrochemical measurement system in the frequency range from $100 \mathrm{kHz}$ to $0.1 \mathrm{~Hz}$ with AC voltage amplitude of $5 \mathrm{mV}$.

\section{Results and discussion}

On the basis of chemical interaction studies for PS,[24] the CPs were intentionally functionalized to form oxygenated $\mathrm{CP}, \mathrm{N}$ doped $\mathrm{CP}$ and $\mathrm{N}, \mathrm{S}$ co-doped $\mathrm{CP}$ using hydrothermal reaction or acid treatment. The surface morphology of carbon fibers in $\mathrm{CP}$ matrix is not affected by doping (Fig. 2a and 2b) and the EDX and elemental mappings indicate the presence and uniform distribution of sulfur, nitrogen and 
oxygen on the surface of N, S co-doped carbon paper (Fig. S2). While the variation of surface chemistry on $\mathrm{CP}$ was observed in Raman and X-ray photoelectron spectroscopy (XPS). As shown in Fig. 3a, the ratio of the D band (at $1350 \mathrm{~cm}^{-1}$, disordered carbon) to the $\mathrm{G}$ band (at $1680 \mathrm{~cm}^{-1}$, graphitic lattice) in Raman spectra increases in the order of pristine $\mathrm{CP}<$ oxygenated $\mathrm{CP}<\mathrm{N}$ doped $\mathrm{CP}<\mathrm{N}, \mathrm{S}$ co-doped $\mathrm{CP}$, indicating that more defects exist in $\mathrm{N}, \mathrm{S}$ doped-CP.[25] XPS analysis demonstrated that the $\mathrm{S}$ and $\mathrm{N}$ content of $\mathrm{N}, \mathrm{S}$ co-doped carbon paper is 4.9 at $\%$ and 5.6 at\% respectively, and $\mathrm{N}$ content of $\mathrm{N}$-doped carbon paper is 5.4 at\%. In Fig. S3a, $\mathrm{C} 1 \mathrm{~s}$ at about $284 \mathrm{eV}$ and $\mathrm{O} 1 \mathrm{~s}$ at about $531 \mathrm{eV}$ are observed in the pristine $\mathrm{CP}$, which become more pronounced in oxygenated CP. The high-resolution C 1s spectra (Fig. S3b) of oxygenated CP can be ascribed to the hydroxyl, epoxide, carbonyl and carboxyl groups, demonstrating $\mathrm{sp}^{2}$ carbon lattice in $\mathrm{CP}$ was oxidized by acid treatment.[26] The new characteristic peak at about $400.0 \mathrm{eV}, 163.0-168.0 \mathrm{eV}$ and $231.0 \mathrm{eV}$ in XPS survey spectra of N, S co-doped CP (Fig. S3a) corresponds to the N $1 s, S 2 p$ and $S 2$ s respectively, confirming the success $N, S$ dual-doing in $N, S$ co-doped CP. The peak at $400 \mathrm{eV}$ in XPS of $\mathrm{N}$ doped $\mathrm{CP}$ also prove that the $\mathrm{N}$ have been integrated onto CP. The S 2p spectrum in the Fig. S3a was expanded to analyze the S dopant in N, S co-doped CP. The peaks in at $163.6 \mathrm{eV}$ and $164.8 \mathrm{eV}$ in Fig. 3b belong to $\mathrm{S}$ atoms bonded with carbon, and the peak at $167-168 \mathrm{eV}$ corresponds to oxidized S species $\left(\mathrm{SO}_{\mathrm{x}}\right)$.[27] As for the $\mathrm{N}$ 1s peaks (Fig. 3c) in $\mathrm{N}$ doped $\mathrm{CP}$, it can be assigned to three $\mathrm{N}$ species: pyridinic-N (398.4 eV), pyrrolic-N (400.0 eV) and quaternary-N (401.5 402.0 eV) which have all been proven to bind with 
LiPS.[24]'[28] While in the N, S co-doped CP (Figure 3d), all three N species still exist in N1s peak but at a different percentage.

$\mathrm{CP} / \mathrm{PCH} / \mathrm{S}$ cathode were prepared by dropping the $\mathrm{Li}_{2} \mathrm{~S}_{6} / \mathrm{CMK}-3$ suspension onto the $\mathrm{CP}$ current collectors and followed by drying. By increasing the $\mathrm{S}$ loading from 1.5 to $9.0 \mathrm{mg} \mathrm{cm}^{-2}$, the interspace between the individual carbon fibers were gradually filled up by the LiPS coated CMK-3 PCH composite where the CMK-3 particles severs as the short-range conductive bridge to maximize the sulfur utilization (Fig. 2c and $2 \mathrm{~d}$ ). The homogenous dispersion of active sulfur materials in the $\mathrm{CP} / \mathrm{PCH} / \mathrm{S}$ cathode originates from the use of soluble PS. Fig. $4 \mathrm{a}$ and $4 \mathrm{~b}$ present the charge-discharge profiles of $\mathrm{N}, \mathrm{S}$ co-doped $\mathrm{CP} / \mathrm{PCH} / \mathrm{S}$ electrode with the sulfur loading of 1.5 and $9.0 \mathrm{mg} \mathrm{cm}^{-2}$ after first discharge, respectively. Fig. S4 shows the first discharge curve in which the high plateau at about $2.3 \mathrm{~V}$ for $\mathrm{Li}_{2} \mathrm{~S}_{8}$ to $\mathrm{Li}_{2} \mathrm{~S}_{6}$ disappears since $\mathrm{Li}_{2} \mathrm{~S}_{6}$ was directly used as an active materials.[11] All these charge/discharge profiles show typical two Li-S plateaus of S cathode. Only a small change in voltage plateaus was observed in charge/discharge curves of these two electrodes, implying the 3D conductive network of $\mathrm{CP}$ can effectively promote fast ionic/electronic transport and rapid charge transfer even at a high sulfur loading. As displayed in Fig. 4c, functional groups on the $\mathrm{CP}$ stabilized long-term cycling performance of sulfur cathode with the sulfur loading of $1.5 \mathrm{mg} \mathrm{cm}^{-2}$. All doped $\mathrm{CP} / \mathrm{PCH} / \mathrm{S}$ cathode show the initial capacity over $1000 \mathrm{mAh} \mathrm{g}^{-1}$ at $0.25 \mathrm{C}$. The pristine $\mathrm{CP} / \mathrm{PCH} / \mathrm{S}$ cathode suffers a fast capacity decay from 950 in the first cycle to $465 \mathrm{mAh} \mathrm{g}^{-1}$ after 500 cycles. Similarly, the capacity of oxygenated CP/PCH/S 
cathode also quickly drop from initial 1020 to $583 \mathrm{mAh} \mathrm{g}^{-1}$ after 500 cycles. However, $\mathrm{N}$-doped CP/PCH/S cathode only drop to a capacity of $745 \mathrm{mAh} \mathrm{g}^{-1}$ after 500 cycles whereas the N, S co-doped CP/PCH/S cathode delivered an initial capacity of 1104 $\mathrm{mAh} \mathrm{g}^{-1}$ and retained to $747 \mathrm{mAh} \mathrm{g}^{-1}$ even after 1000 cycles, corresponding to an ultralow capacity fading of $0.033 \%$ per cycle which is one of best performance in all reported CP or binder-free carbon/sulfur cathodes reported to date.[7]'[29-31]

The nature of bonding between hetero-atoms dopant on CP and high-order LiPS was analyzed using XPS. The functionalized CP was dipped with $\mathrm{Li}_{2} \mathrm{~S}_{6}$-DME solution and then dried for XPS analysis (Fig. 5). The symmetric peak at $55.5 \mathrm{eV}$ in all Li spectra of $\mathrm{CP} / \mathrm{Li}_{2} \mathrm{~S}_{6}$ is attributed to $\mathrm{Li}-\mathrm{S}$ bond. In pristine $\mathrm{CP} / \mathrm{Li}_{2} \mathrm{~S}_{6}$ sample, only a peak at $55.5 \mathrm{eV}$ appears, implying no chemical bonding to $\mathrm{CP}$ (Fig. 5a). In general, $\mathrm{N}$ dopants can increase the surface basicity of $\mathrm{CP}$, strengthening the Lewis acid-base interaction between CP and Lewis acidic Li in LiPS.[32][33] These Lewis acid-base interaction seem much stronger than the polar to polar interaction between the oxygenated CP and polysulfide anion species, as evidenced by XPS (Fig. 5a-5c) of $\mathrm{Li}_{2} \mathrm{~S}_{6}$ treated CP. An additional peak at $56.5 \mathrm{eV}$ in $\mathrm{N}$ doped $\mathrm{CP}$ and N, S co-doped CP is assigned to Li-N bond.[33] The intensity of Li-N bond of N, S co-doped CP (Fig. 5c) is obviously higher than that of $\mathrm{N}$ doped CP (Fig. 5b). Moreover, the peak at 162.7 eV in $\mathrm{S} 2 \mathrm{p}$ spectra of $\mathrm{N}, \mathrm{S}$ co-doped $\mathrm{CP} / \mathrm{Li}_{2} \mathrm{~S}_{6}$ sample (Fig. $5 \mathrm{~d}$ ) can be assigned to terminal sulfur $\left(\mathrm{S}_{\mathrm{T}}^{-1}\right)$ in $\mathrm{Li}_{2} \mathrm{~S}_{6}$ which is slightly higher than its standard value.[34] We ascribe the shift of $\mathrm{S}_{\mathrm{T}}^{-1}$ to higher binding energy to the interaction between $\mathrm{S}_{\mathrm{T}}^{-1}$ and positively charged dopant S in N, S co-doped CP, as reported previously.[33] Previous 
DFT calculations show that pyridinic-N with a lone pair of electrons in six-atoms ring provide an adsorption energy of LiPS about $-50 \mathrm{kcal} \mathrm{mol}^{-1}$, which is significantly higher than that of pyrrolic-N $\left(-30 \mathrm{kcal} \mathrm{mol}^{-1}\right)$ and quaternary-N $\left(-20 \mathrm{kcal} \mathrm{mol}^{-1}\right) \cdot[24]$ Therefore, except for the interaction between high-order PS and S dopant in doped CP, the distribution of $\mathrm{N}$ species may be another reason for the different cycling stability of cathode using the two $\mathrm{N}$ containing CPs. From the Table. S1, the higher specific surface basicity of N, S co-doped CP also demonstrate its stronger PS chemisorption than that of N-doped CP. These theoretical studies adequately explain the excellent cycling performance of N, S co-doped CP sulfur cathode.

Since N, S co-doped CP cathode show the best electrochemical performance among all doped CP cathodes at $1.5 \mathrm{mg} \mathrm{cm}^{-2}$ loading, $\mathrm{N}, \mathrm{S}$ co-doping is selected to functionalize $\mathrm{CP}$ and/or $\mathrm{PCH}$ to understand which one play more important role in stabilizing the cycling capacity when $\mathrm{S}$ loading reach to $9.0 \mathrm{mg} \mathrm{cm}{ }^{-2}$. The cycling behavior of four $\mathrm{CP} / \mathrm{PCH} / \mathrm{S}$ cathodes (un-doped PCH \&CP, Doped PCH, Doped CP and Doped $\mathrm{PCH} \& \mathrm{CP}$ ) with the same $\mathrm{S}$ loading of $9.0 \mathrm{mg} \mathrm{cm}^{-2}$ were tested at $0.25 \mathrm{C}$. As shown in Fig. 6a, the high $\mathrm{S}$ loading cathode with pristine $\mathrm{CP}$ and $\mathrm{CMK}-3 \mathrm{PCH}$ suffers a serious capacity decay from $732 \mathrm{mAh} \mathrm{g}^{-1}$ (1st cycle) to $390 \mathrm{mAh} \mathrm{g}^{-1}$ (168th cycle) and then rapidly decrease to almost zero. The "sudden death" may result from increasing side reaction between dissolved polysulfide and lithium metal.[13] By simply inducing functional groups on $\mathrm{CMK}-3 \mathrm{PCH}$ via the carbonization of ionic liquid ([PP14][TFSI]) (Fig. S5) in electrode, both the capacity (941 $\mathrm{mAh} \mathrm{g}^{-1}$ for $1 \mathrm{st}$ discharge) and capacity retention (497 $\mathrm{mAh} \mathrm{g}^{-1}$ after 200 cycles) of the cathode were 
slightly improved due to chemical adsorption of high-order PS to doped PCH. However, the high S loading cathode in which only CP collector was changed to a functionalized one exhibits an exceptionally effective enhancement of cycling stability. This cathode delivers an initial discharge capacity of $960 \mathrm{mAh} \mathrm{g}^{-1}$ and remains at 810 $\mathrm{mAh} \mathrm{g}^{-1}$ after 200 cycles. The best performance was achieved when both PCH and CP were doped by $\mathrm{N}$ and $\mathrm{S}$. The capacity only drops from $1013 \mathrm{mAh} \mathrm{g}^{-1}$ at $1^{\text {st }}$ cycle to $789 \mathrm{mAh} \mathrm{g}^{-1}$ at $300^{\text {th }}$ cycle. Table. 1 summarizes many reports about sulfur cathode using 3D conductive carbon current collector [7,35-39]. In contrast to these reports, functionalization of carbon paper current collector can significantly enhance cycling stability even at much high sulfur loading, which guarantee the high energy density of Li-S battery. Additionally, the enhancement in cycling stability of high sulfur loading cathode is in order of pristine $\mathrm{CP}+\mathrm{PCH}$ <pristine $\mathrm{CP}+$ doped $\mathrm{PCH}<$ doped $\mathrm{CP}+$ undoped $\mathrm{PCH}<$ doped $\mathrm{CH}+$ doped $\mathrm{PCH}$, due to increase in ability of absorption to high-order PS in electrode. As shown in Tab. S1 and Fig.6b, the function groups on either current collector or sulfur host can tune the surface basicity of carbon and immobilize LiPS, and both have similar specific surface basicity. However, due to high mass ratio of carbon paper to carbon host, large total surface basic sites of $\mathrm{CP}$ allow the CP current collector to chemically adsorb more high-order polysulfide than that on sulfur host, which can more effectively extend the cycle life of high S loaded cathode.

Except the long-term cycling tests, doped $\mathrm{CP} /$ doped $\mathrm{PCH} / \mathrm{S}$ cathode also shows a better rate performance than that of pristine $\mathrm{CP} /$ pure $\mathrm{PCH} / \mathrm{S}$ cathode with a high 
sulfur loading of $9.0 \mathrm{mg} \mathrm{cm}^{-2}$ (Fig. S5). Compared with pristine $\mathrm{CP} /$ pure $\mathrm{PCH} / \mathrm{S}$ cathode, the capacity of doped $\mathrm{CP} /$ doped $\mathrm{PCH} / \mathrm{S}$ cathode decrease much less sensitive to the current rates. It is worth noting that the doped $\mathrm{CP} /$ doped $\mathrm{PCH} / \mathrm{S}$ cathode exhibits a high capacity of $565 \mathrm{mAh} \mathrm{g}^{-1}$ at a high rate of $2 \mathrm{C}$. The improved capability to maintain high electronic/ionic conduction of doped $\mathrm{CP} / \mathrm{PCH} / \mathrm{S}$ cathode is also proved by small amount of resident $S_{8}$ in fully discharged cathode after 200 cycles. In Fig. $7 \mathrm{a}$ and $7 \mathrm{~b}$, the S $2 \mathrm{p}$ XPS spectra of fully discharged pristine CP/PCH/S cathode shows the much stronger $\mathrm{S}_{8}$ peaks $(164.1 \mathrm{eV})$ than that of doped CP/PCH/S cathode after 200 cycles, indicating the existence of a large amount of residual sulfur that was insulated to current collector in pristine $\mathrm{CP} / \mathrm{PCH} / \mathrm{S}$ cathode. The poor electronic conductivity increase the interface resistance, as demonstrated by the electrochemical impedance spectra (EIS) of two cycled CP/S cathode (Fig. S7). The morphological change of these two cathodes with $\mathrm{S}$ loading of $9.0 \mathrm{mg} \mathrm{cm}^{-2}$ after 200 cycles provides direct evidence for change in electronic conductive network (Fig. 7c and 7d). The doped $\mathrm{CP} / \mathrm{PCH} / \mathrm{S}$ cathode after 200 cycles still maintain the similar structure to that of cathode before cycling, while 3D CP collapse in pristine $\mathrm{CP} / \mathrm{PCH} / \mathrm{S}$ cathode due to uneven but large volume change of $\mathrm{S}$ inside the pore/hole of $\mathrm{CP}$ stress/strain. The chemisorption of PS on doped CP render a uniform re-deposition of sulfur (on charge) or $\mathrm{Li}_{2} \mathrm{~S}$ (on discharge) in the $\mathrm{CP}$ matrix support that gives rise to the stable and higher electronic and ionic conductivity of cathode.[40] This is in accord with the electrochemical performance and XPS results of these cathodes.

The instability of lithium anode was usually hidden in lab Li-S cells with low 
sulfur-loading electrode due to the excess amount of lithium metal anode.[6,13] However, high sulfur loading and limited amount of electrolyte are required in high energy Li-S batteries. In the cells with pristine $\mathrm{CP}$ current collector, the concentration of LiPS can easily reach saturation in the cathode,[30] and then some unanchored LiPS will diffuse out and react with anode. The continuous lithium corrosion will consume the LiPS and formation of insulating interphase, leading to capacity fading, as evidenced by surface morphology change of lithium anode coupling with S loading of $9.0 \mathrm{mg} \mathrm{cm}{ }^{-2}$ after 200 cycles. The passivation layer on cycled lithium anode consists of $\mathrm{Li}_{2} \mathrm{~S}$ nanoparticles (Fig. 8a). The thickness of passivation layer on $\mathrm{Li}$ is about $40-60 \mu \mathrm{m}$ in cell using doped CP current collector (Fig. 8c), which is far less than that in the cell with pristine carbon CP current collector $(220-250 \mu \mathrm{m})$ (Fig. 8b), implying a much stronger chemical interactions between doped CP and high-order LiPS. The increase in insulating film will highly increase the cell impedance (Fig. S7) and also demonstrated by the rapid capacity drop of the S/pristine CP cathode in the charge/discharge cycles.[6,13]

In summary, the chemisorption of high-order LiPS by functional groups on the current collector and carbon host can greatly improve the sulfur utilization and cycling performance of high sulfur loading cathode. The N, S co-doped CP/PCH/S cathode with $\mathrm{S}$ loading of $9.0 \mathrm{mg} \mathrm{cm} \mathrm{cm}^{-2}$ show the best present the best capacity retention of $77.8 \%$ after 300 cycles, due to the synergistic effect of multi-dopant $(\mathrm{N}$, S) for the enhanced surface Lewis basicity of CP that facilitate the adsorption of LiPS. Compared with sulfur host, the surface properties of current collector plays a major 
role in chemical absorption of LiPS due to abundant chemical sites on it. Moreover, the chemical absorption of LiPS in cathode also reduce the side reaction of lithium anode and mechanical destruction of electronic conductive network in S/CP cathode. Our findings not only testify the importance of chemical adsorption of current collector on electrochemical performance of sulfur cathode, but also shed light on the design of ultrahigh loading sulfur electrode to commercialize high energy Li-S batteries.

\section{Acknowledgements}

The authors thank Dr. Karen J. Gaskell at the Surface Analysis Center of University of Maryland for the help on the XPS test and data analysis. X. Wang's fellowship was supported by China Scholarship Council (No.201406370037). This work was also supported by Nanostructures for Electrical Energy Storage (NEES), an Energy Frontier Research Center funded by the U.S. Department of Energy, Office of Science, Office of Basic Energy Sciences under Award No. DESC0001160.

\section{References}

[1] P.G. Bruce, S. a. Freunberger, L.J. Hardwick, J.-M. Tarascon, Li-O2 and Li-S batteries with high energy storage, Nat. Mater. 11 (2011) 172-172. doi:10.1038/nmat3237.

[2] A. Manthiram, Y. Fu, S. Chung, C. Zu, Y. Su, Rechargeable Lithium - Sulfur Batteries, Chem. Rev. 114 (2014) 11751-87. doi:10.1021/cr500062v.

[3] X. Fang, H. Peng, A Revolution in Electrodes: Recent Progress in Rechargeable Lithium-Sulfur Batteries, Small. 11 (2015) 1488-1511. doi:10.1002/smll.201402354.

[4] M. Hagen, S. Dörfler, P. Fanz, T. Berger, R. Speck, J. Tübke, H. Althues, M.J. Hoffmann, C. Scherr, S. Kaskel, Development and costs calculation of lithium-sulfur cells with high sulfur load and binder free electrodes, J. Power Sources. 224 (2013) 260-268. 
doi:10.1016/j.jpowsour.2012.10.004.

[5] N. Ding, S.W. Chien, T.S.A. Hor, Z. Liu, Y. Zong, Key parameters in design of lithium sulfur batteries, J. Power Sources. 269 (2014) 111-116. doi:10.1016/j.jpowsour.2014.07.008.

[6] D. Lv, J. Zheng, Q. Li, X. Xie, S. Ferrara, Z. Nie, L.B. Mehdi, N.D. Browning, J.G. Zhang, G.L. Graff, J. Liu, J. Xiao, High Energy Density Lithium-Sulfur Batteries: Challenges of Thick Sulfur Cathodes, Adv. Energy Mater. 5 (2015) 1-8. doi:10.1002/aenm.201402290.

[7] S.H. Chung, A. Manthiram, Low-cost, porous carbon current collector with high sulfur loading for lithium-sulfur batteries, Electrochem. Commun. 38 (2014) 91-95. doi:10.1016/j.elecom.2013.11.008.

[8] K. Wang, S. Luo, Y. Wu, X. He, F. Zhao, J. Wang, K. Jiang, S. Fan, Super-aligned carbon nanotube films as current collectors for lightweight and flexible lithium ion batteries, Adv. Funct. Mater. 23 (2013) 846-853. doi:10.1002/adfm.201202412.

[9] Z. Ma, Z. Li, K. Hu, D. Liu, J. Huo, S. Wang, The enhancement of polysulfide absorbsion in Li-S batteries by hierarchically porous CoS2/carbon paper interlayer, J. Power Sources. 325 (2016) 71-78. doi:10.1016/j.jpowsour.2016.04.139.

[10] C. Zu, Y.-S. Su, Y. Fu, A. Manthiram, Improved lithium-sulfur cells with a treated carbon paper interlayer., Phys. Chem. Chem. Phys. 15 (2013) 2291-7. doi:10.1039/c2cp43394j.

[11] J. Yan, X. Liu, H. Qi, W. Li, Y. Zhou, M. Yao, B. Li, High-Performance Lithium-Sulfur Batteries with a Cost-Effective Carbon Paper Electrode and High Sulfur-Loading, Chem. Mater. 27 (2015) 6394-6401. doi:10.1021/acs.chemmater.5b02533.

[12] A. Schneider, C. Suchomski, H. Sommer, J. Janek, T. Brezesinski, Free-standing and binder-free highly N-doped carbon/sulfur cathodes with tailorable loading for high-areal-capacity lithium-sulfur batteries, J. Mater. Chem. A. 3 (2015) 20482-20486. doi:10.1039/C5TA06394A.

[13] L. Qie, C. Zu, A. Manthiram, A High Energy Lithium-Sulfur Battery with Ultrahigh-Loading Lithium Polysulfi de Cathode and its Failure Mechanism, Adv. Energy Mater. (2016) 1-7. doi:10.1002/aenm.201502459.

[14] Q. Pang, X. Liang, C.Y. Kwok, L.F. Nazar, Review-The Importance of Chemical Interactions between Sulfur Host Materials and Lithium Polysulfides for Advanced Lithium-Sulfur Batteries, J. Electrochem. Soc. 162 (2015) A2567-A2576. doi:10.1149/2.0171514jes. 
[15] G. Zhou, L.C. Yin, D.W. Wang, L. Li, S. Pei, I.R. Gentle, F. Li, H.M. Cheng, Fibrous hybrid of graphene and sulfur nanocrystals for high-performance lithium-sulfur batteries, ACS Nano. 7 (2013) 5367-5375. doi:10.1021/nn401228t.

[16] G. Zhou, E. Paek, G.S. Hwang, A. Manthiram, High-performance lithium-sulfur batteries with a self-supported, 3D Li2S-doped graphene aerogel cathodes, Adv. Energy Mater. 6 (2016) 1501355. doi:10.1002/aenm.201501355.

[17] H. Li, X. Yang, X. Wang, M. Liu, F. Ye, J. Wang, Y. Qiu, W. Li, Y. Zhang, Dense integration of graphene and sulfur through the soft approach for compact lithium/sulfur battery cathode, Nano Energy. 12 (2015) 468-475. doi:10.1016/j.nanoen.2015.01.007.

[18] J. Liu, W. Li, L. Duan, X. Li, L. Ji, Z. Geng, K. Huang, L. Lu, L. Zhou, Z. Liu, W. Chen, L. Liu, S. Feng, Y. Zhang, A Graphene-like Oxygenated Carbon Nitride Material for Improved Cycle-Life Lithium/Sulfur Batteries, Nano Lett. 15 (2015) 5137-5142. doi:10.1021/acs.nanolett.5b01919.

[19] Y.C. Qiu, W.F. Li, W. Zhao, G.Z. Li, Y. Hou, M.N. Liu, L.S. Zhou, F.M. Ye, H.F. Li, Z.H. Wei, S.H. Yang, W.H. Duan, Y.F. Ye, J.H. Guo, Y.G. Zhang, High-Rate, Ultra long Cycle-Life Lithium/Sulfur Batteries Enabled by Nitrogen-Doped Graphene, Nano Lett. 14 (2014) 4821-4827. doi:10.1021/n15020475.

[20] J. Song, T. Xu, M.L. Gordin, P. Zhu, D. Lv, Y.B. Jiang, Y. Chen, Y. Duan, D. Wang, Nitrogen-doped Mesoporous carbon promoted chemical adsorption of sulfur and fabrication of high-Areal-capacity sulfur cathode with exceptional cycling stability for lithium-sulfur batteries, Adv. Funct. Mater. 24 (2014) 1243-1250. doi:10.1002/adfm.201302631.

[21] L. Li, G. Zhou, L. Yin, N. Koratkar, F. Li, H.M. Cheng, Stabilizing sulfur cathodes using nitrogen-doped graphene as a chemical immobilizer for Li[Formula presented]S batteries, Carbon N. Y. 108 (2016) 120-126. doi:10.1016/j.carbon.2016.07.008.

[22] G. Zhou, E. Paek, G.S. Hwang, A. Manthiram, Long-life Li/polysulphide batteries with high sulphur loading enabled by lightweight three-dimensional nitrogen/sulphur-codoped graphene sponge, Nat. Commun. 6 (2015) 7760. doi:10.1038/ncomms8760.

[23] L. Ji, M. Rao, H. Zheng, L. Zhang, Y. Li, W. Duan, J. Guo, E.J. Cairns, Y. Zhang, Graphene oxide as a sulfur immobilizer in high performance lithium/sulfur cells, J. Am. Chem. Soc. 133 (2011) 18522-18525. doi:10.1021/ja206955k. 
[24] J.-J. Chen, R.-M. Yuan, J.-M. Feng, Q. Zhang, J.-X. Huang, G. Fu, M.-S. Zheng, B. Ren, Q.-F. Dong, Conductive Lewis Base Matrix to Recover the Missing Link of $\mathrm{Li}_{2} \mathrm{~S}_{8}$ during the Sulfur Redox Cycle in Li-S Battery, Chem. Mater. 27 (2015) 2048-2055. doi:10.1021/cm5044667.

[25] C. Domínguez, F.J. Pérez-Alonso, S.A. Al-Thabaiti, S.N. Basahel, A.Y. Obaid, A.O. Alyoubi, J.L. Gómez De La Fuente, S. Rojas, Effect of N and S co-doping of multiwalled carbon nanotubes for the oxygen reduction, Electrochim. Acta. 157 (2015) 158-165. doi:10.1016/j.electacta.2015.01.031.

[26] L. Zhang, L. Ji, P.-A. Glans, Y. Zhang, J. Zhu, J. Guo, Electronic structure and chemical bonding of a graphene oxide-sulfur nanocomposite for use in superior performance lithium-sulfur cells., Phys. Chem. Chem. Phys. 14 (2012) 13670-5. doi:10.1039/c2cp42866k.

[27] S. Niu, W. Lv, G. Zhou, Y. He, B. Li, Q.-H. Yang, F. Kang, N and S co-doped porous carbon spheres prepared using $\langle\mathrm{scp}>1</ \mathrm{scp}>$-cysteine as a dual functional agent for high-performance lithium-sulfur batteries, Chem. Commun. 51 (2015) 1-4. doi:10.1039/C5CC07226C.

[28] X. Wang, Z. Zhang, Y. Qu, Y. Lai, J. Li, Nitrogen-doped graphene/sulfur composite as cathode material for high capacity lithium-sulfur batteries, J. Power Sources. 256 (2014) 361-368. doi:10.1016/j.jpowsour.2014.01.093.

[29] X. Huang, B. Sun, K. Li, S. Chen, G. Wang, Mesoporous graphene paper immobilised sulfur as a flexible electrode for lithium-sulfur batteries, J. Mater. Chem. A. 1 (2013) 13484. doi:10.1039/c3ta12826a.

[30] L. Miao, W. Wang, K. Yuan, Y. Yang, A. Wang, A lithium-sulfur cathode with high sulfur loading and high capacity per area: a binder-free carbon fiber cloth-sulfur material, Chem. Commun. 50 (2014) 13231-13234. doi:10.1039/c4cc03410d.

[31] K. Fu, Y. Li, M. Dirican, C. Chen, Y. Lu, J. Zhu, Y. Li, L. Cao, P.D. Bradford, X. Zhang, Sulfur gradient-distributed CNF composite: a self-inhibiting cathode for binder-free lithium-sulfur batteries, Chem. Commun. 50 (2014) 10277-10280. doi:10.1039/c4cc04970e.

[32] J. Song, M.L. Gordin, T. Xu, S. Chen, Z. Yu, H. Sohn, J. Lu, Y. Ren, Y. Duan, D. Wang, Strong lithium polysulfide chemisorption on electroactive sites of nitrogen-doped carbon composites for high-performance lithium-sulfur battery cathodes, Angew. Chemie - Int. Ed. 54 (2015) 4325-4329. doi:10.1002/anie.201411109.

[33] Q. Pang, J. Tang, H. Huang, X. Liang, C. Hart, K.C. Tam, L.F. Nazar, A Nitrogen and Sulfur 
Dual-Doped Carbon Derived from Polyrhodanine@Cellulose for Advanced Lithium-Sulfur Batteries, Adv. Mater. 27 (2015) 6021-6028. doi:10.1002/adma.201502467.

[34] X. Liang, C. Hart, Q. Pang, A. Garsuch, T. Weiss, L.F. Nazar, A highly efficient polysulfide mediator for lithium-sulfur batteries, Nat. Commun. 6 (2015) 5682. doi:10.1038/ncomms6682.

[35] Z. Yuan, H.J. Peng, J.Q. Huang, X.Y. Liu, D.W. Wang, X.B. Cheng, Q. Zhang, Hierarchical free-standing carbon-nanotube paper electrodes with ultrahigh sulfur-loading for lithium-sulfur batteries, Adv. Funct. Mater. 24 (2014) 6105-6112. doi:10.1002/adfm.201401501.

[36] S. Walu, C. Barchasz, R. Bouchet, J. Martin, J. Leprêtre, F. Alloin, Investigation of non-woven carbon paper as a current collector for sulfur positive electrode — Understanding of the mechanism and potential applications for Li / S batteries, Electrochim. Acta. 211 (2016) 697-703. doi:10.1016/j.electacta.2016.05.204.

[37] Z. Cao, J. Zhang, Y. Ding, Y. Li, M. Shi, H. Yue, Y. Qiao, Y. Yin, S. Yang, In situ synthesis of flexible elastic $\mathrm{N}$-doped carbon foam as a carbon current collector and interlayer for high-performance lithium sulfur batteries, J. Mater. Chem. A. 4 (2016) 8636-8644. doi:10.1039/C6TA01855F.

[38] S. Chung, A. Manthiram, Nano-cellular carbon current collectors with stable cyclability for Li - S batteries, J. Mater. Chem. A. 1 (2013) 9590-9596. doi:10.1039/c3ta11819c.

[39] J. He, Y. Chen, P. Li, F. Fu, Z. Wang, W. Zhang, Three-dimensional CNT/graphene-sulfur hybrid sponges with high sulfur loading as superior-capacity cathodes for lithium-sulfur batteries, J. Mater. Chem. A. 3 (2015) 18605-18610. doi:10.1039/C5TA04445F.

[40] Q. Pang, D. Kundu, M. Cuisinier, L.F. Nazar, Surface-enhanced redox chemistry of polysulphides on a metallic and polar host for lithium-sulphur batteries, Nat Commun. 5 (2014) 4759. doi:10.1038/ncomms5759. 


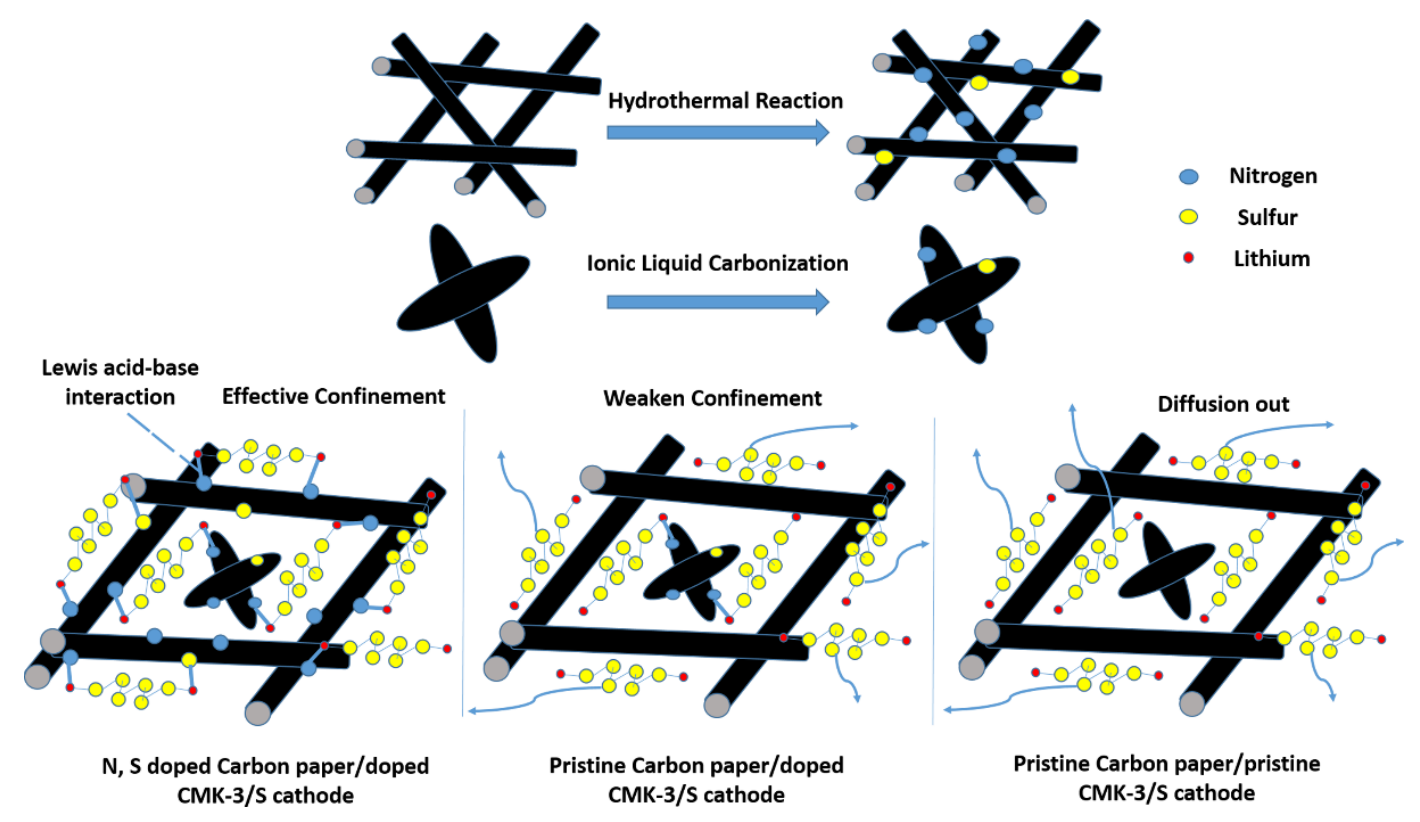

Fig. 1 Schematic representation of the synthesis process of $\mathrm{CP} / \mathrm{PCH} / \mathrm{S}$ cathode and the interaction of PS in pristine $\mathrm{CP} / \mathrm{PCH} / \mathrm{S}$ and $\mathrm{N}, \mathrm{S}$ doped $\mathrm{CP} / \mathrm{PCH} / \mathrm{S}$ cathode. 


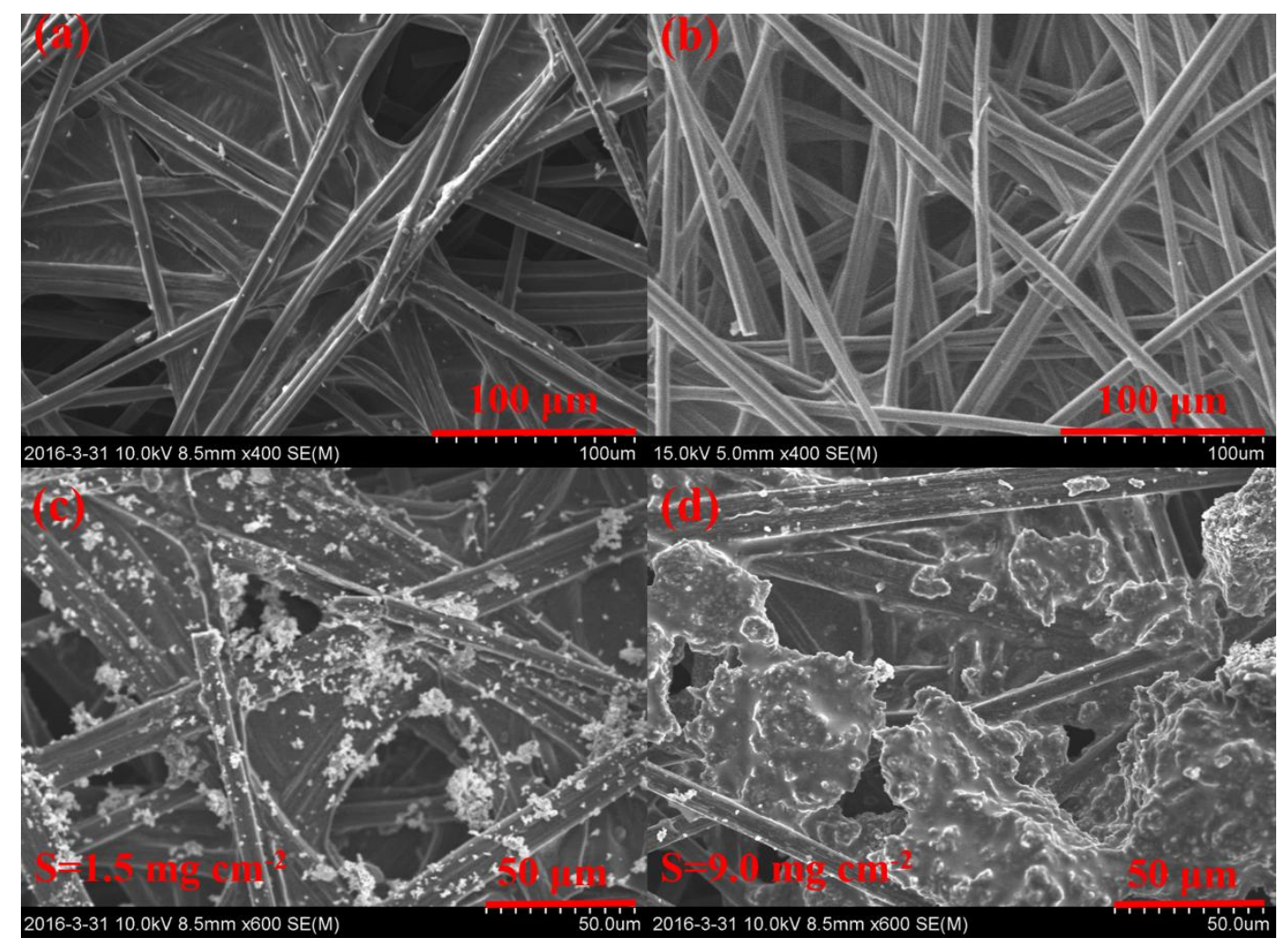

Fig. 2 SEM images of (a) pristine CP; (b) N, S co doped CP; (c) N, S co-doped $\mathrm{CP} / \mathrm{PCH} / \mathrm{S}$ cathode with $\mathrm{S}$ loading of $1.5 \mathrm{mg} \mathrm{cm}^{-2}$; (d) $\mathrm{N}, \mathrm{S}$ co-doped $\mathrm{CP} / \mathrm{PCH} / \mathrm{S}$ cathode with $\mathrm{S}$ loading of $9.0 \mathrm{mg} \mathrm{cm}^{-2}$. The diameter of carbon fiber in $\mathrm{CP}$ is $5-10 \mu \mathrm{m}$. 

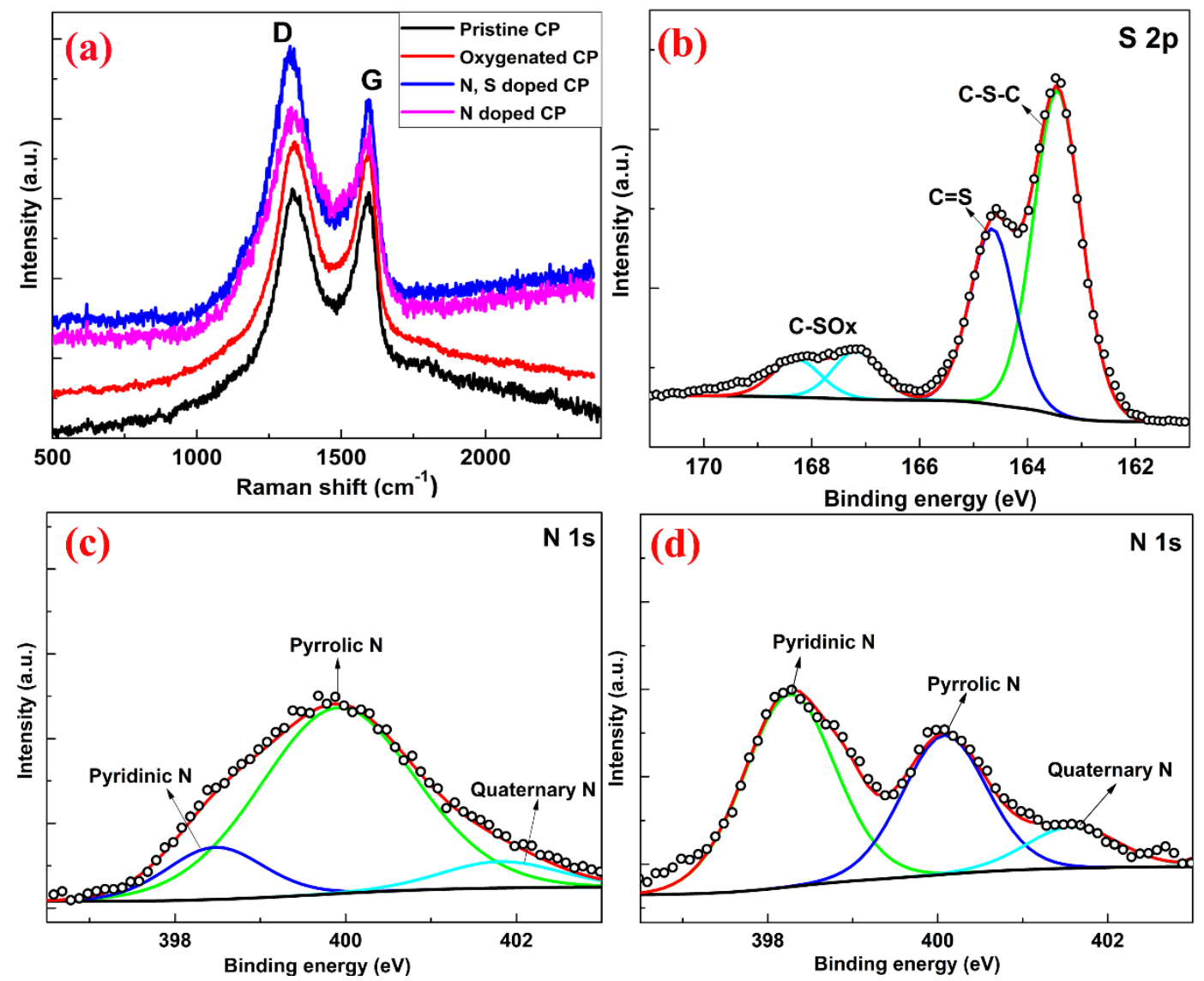

Fig. 3 (a) Raman spectra of pristine CP and chemical modified CPs; (b) S 2p XPS spectra of N, S co-doped CP; (c) N 1s spectra of N-doped CP and (d) N, S co-doped CP. 

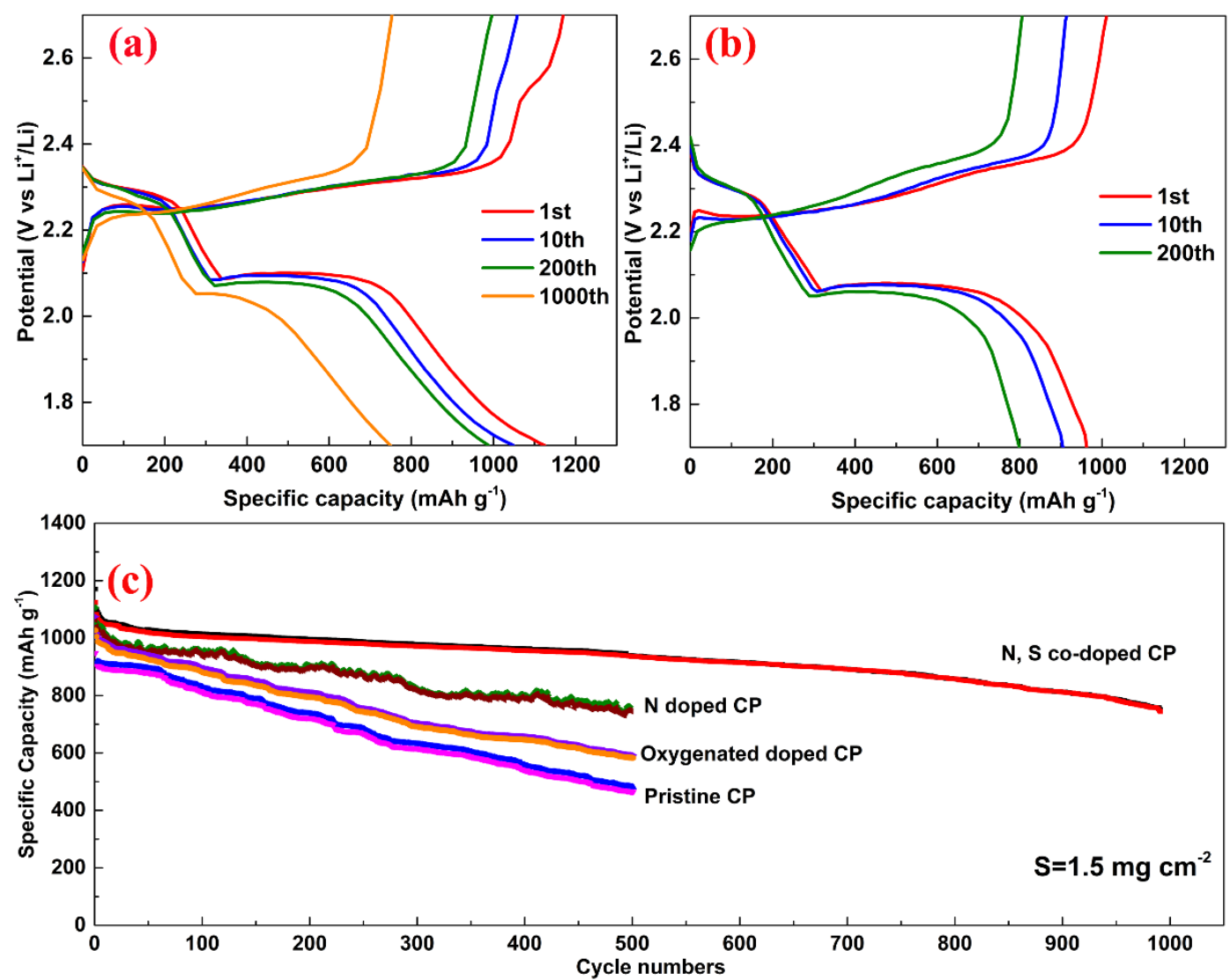

Fig. 4 Galvanostatic voltage profiles of (a) low S loading N, S co-doped CP/PCH/S cathode $\left(1.5 \mathrm{mg} \mathrm{cm}^{-2}\right)$ and (b) high $\mathrm{S}$ loading $\mathrm{N}, \mathrm{S}$ co-doped $\mathrm{CP} / \mathrm{PCH} / \mathrm{S}$ cathode $(9.0$ $\mathrm{mg} \mathrm{cm}{ }^{-2}$ ) in different cycles at current rate of $0.2 \mathrm{C}$. (c) Cycling performance of pristine $\mathrm{CP} / \mathrm{PCH} / \mathrm{S}$ cathode with the sulfur loading of $1.5 \mathrm{mg} \mathrm{cm}$, oxygenated $\mathrm{CP} / \mathrm{PCH} / \mathrm{S}, \mathrm{N}$ doped $\mathrm{CP} / \mathrm{PCH} / \mathrm{S}$ and $\mathrm{N}, \mathrm{S}$ co-doped $\mathrm{CP} / \mathrm{PCH} / \mathrm{S}$ cathode at $0.25 \mathrm{C}$. 

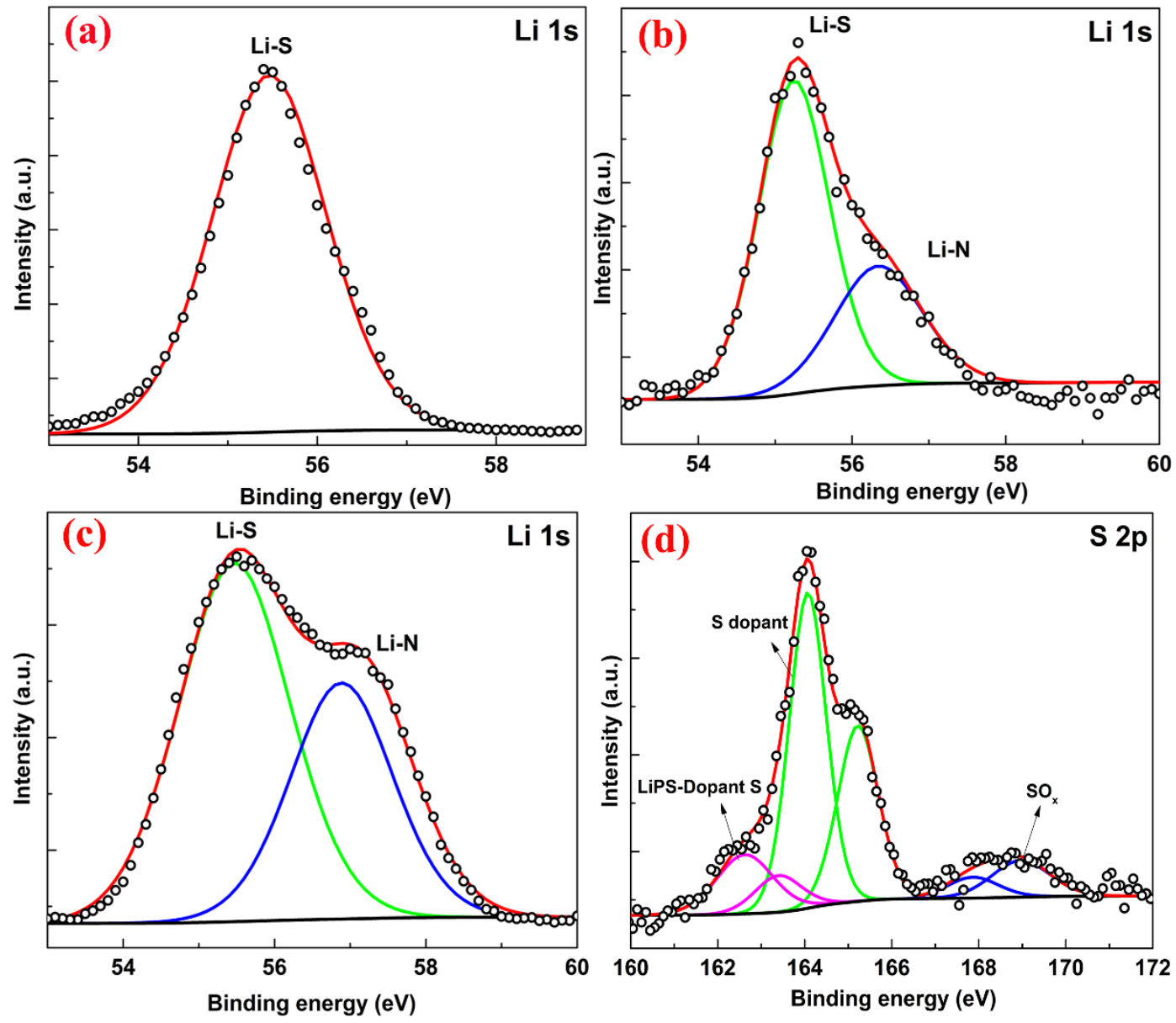

Fig. 5 (a) XPS spectra of $\mathrm{Li}_{2} \mathrm{~S}_{6}$ treated pristine $\mathrm{CP}$, (b) $\mathrm{N}$ doped $\mathrm{CP}$ and (c) $\mathrm{N}$, S-doped CP; (d) S 2p XPS spectra of $\mathrm{Li}_{2} \mathrm{~S}_{6}$ treated N, S-doped CP. The binding energy of S 2p1/2 and S 2p3/2 for $S$ are 163.8 and $165.0 \mathrm{eV}$. 


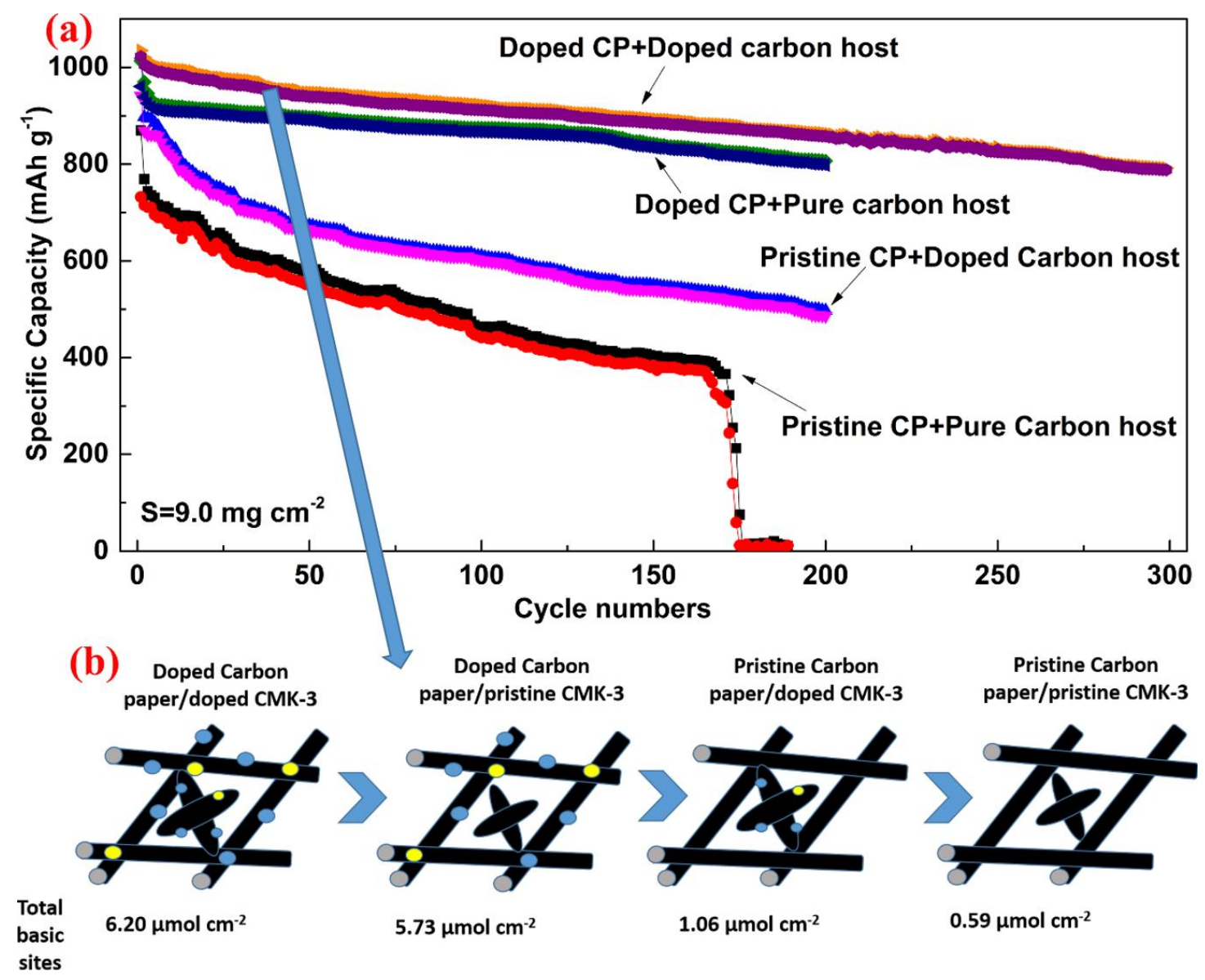

Fig. 6 (a) Cycling performance of high sulfur loading $\left(9.0 \mathrm{mg} \mathrm{cm} \mathrm{cm}^{-2}\right)$ cathode with different (pure or doped) $\mathrm{CPs}$ and carbon sulfur hosts $(\mathrm{CP} / \mathrm{PCH} / \mathrm{S}$ cathode); (b) Depicts of surface basicity of high sulfur loading $\left(9.0 \mathrm{mg} \mathrm{cm}^{-2}\right)$ cathode with different (pure or doped) CPs and carbon sulfur hosts. 

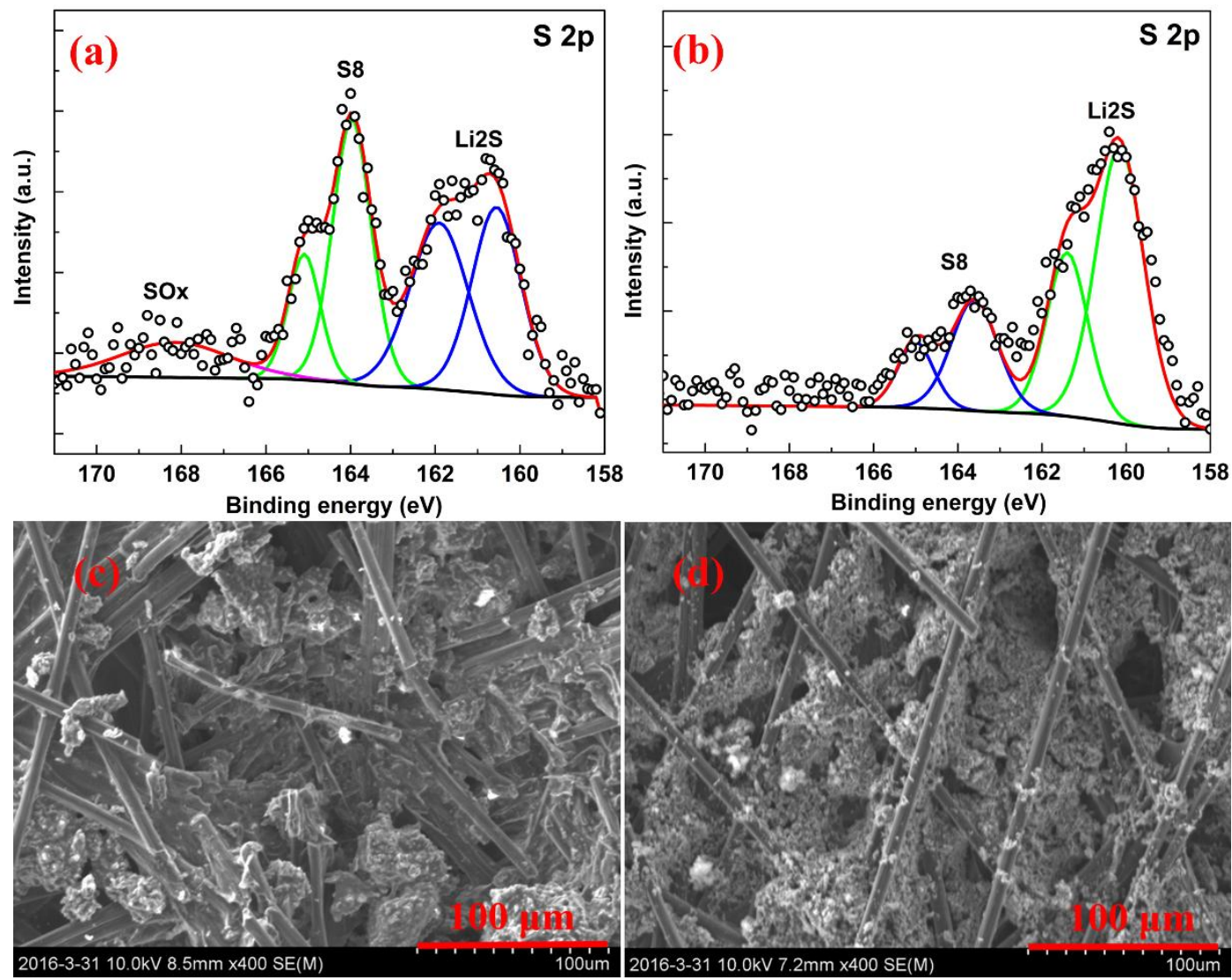

Fig. 7 S 2p XPS spectra of cycled (a) pristine CP/PCH/S and (b) N, S co-doped $\mathrm{CP} / \mathrm{PCH} / \mathrm{S}$ cathode after 200 cycles; SEM images of (c) pristine CP/PCH/S cathode and (d) N, S co-doped CP/PCH/S with a high sulfur loading of $9.0 \mathrm{mg} \mathrm{cm}^{-2}$ after 200 cycles. 


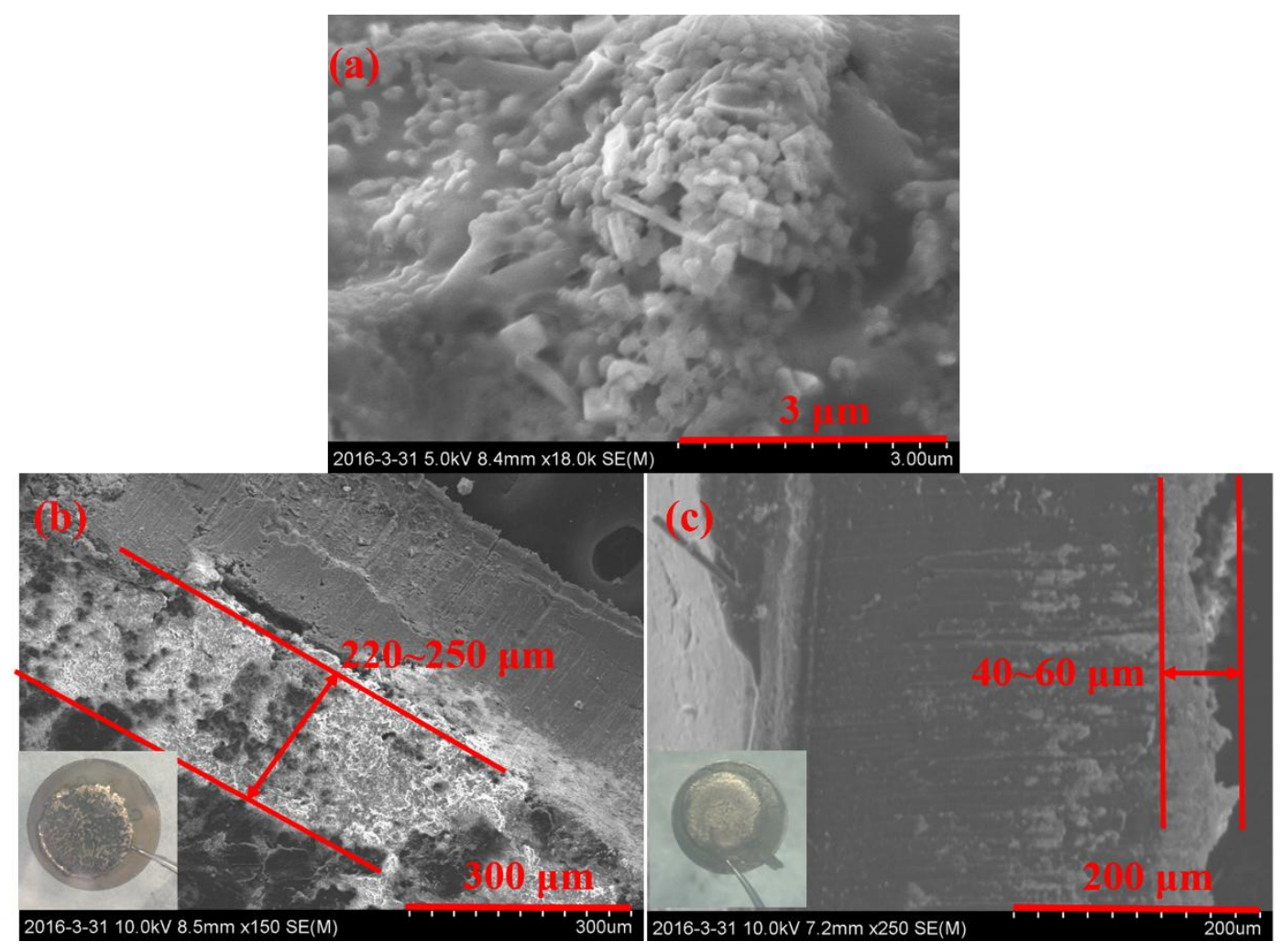

Fig. 8 (a) surface SEM image of cycled lithium anode; cross-sectional SEM images of cycled lithium anode from Li-S cells with (b) pristine CP/PCH/S and (d) N, S co-doped $\mathrm{CP} / \mathrm{PCH} / \mathrm{S}$ cathode with a high sulfur loading of $9.0 \mathrm{mg} \mathrm{cm}^{-2}$. Inset of (b) and (c) are the corresponding photograph of surface of cycled lithium anode. 
Tab.1 Summary of Li-S battery using 3D conductive carbon nanostructured current collectors.

\begin{tabular}{|c|l|l|l|}
\hline Samples & Capacity decay & Current rate & Sulfur loading \\
\hline $\begin{array}{c}\text { Carbon paper[7] } \\
\text { Hierarchical } \\
\text { carbon-nanotube } \\
\text { paper[35] }\end{array}$ & $0.3 \%$ up to 50 cycles & $0.2 \mathrm{C}$ & $2.3 \mathrm{mg} \mathrm{cm}^{-2}$ \\
\hline $\begin{array}{c}\text { Non-woven carbon } 150 \text { cycles } \\
\text { paper[36] }\end{array}$ & $0.79 \%$ up to 40 cycles & $0.05 \mathrm{C}$ & $6.3 \mathrm{mg} \mathrm{cm}^{-2}$ \\
\hline $\begin{array}{c}\text { Flexible N-doped } \\
\text { carbon foam[37] }\end{array}$ & $0.19 \%$ up to 100 cycles & $0.5 \mathrm{C}$ & $1.2 \mathrm{mg} \mathrm{cm}^{-2}$ \\
\hline $\begin{array}{c}\text { Nano-cellular } \\
\text { carbon[38] }\end{array}$ & $0.27 \%$ up to 100 cycles & $0.1 \mathrm{C}$ & $2.2 \mathrm{mg} \mathrm{cm}^{-2}$ \\
\hline $\begin{array}{c}\text { CNT/graphene } \\
\text { sponge[39] }\end{array}$ & $0.087 \%$ up to 200 & $0.2 \mathrm{C}$ & $1.0 \mathrm{mg} \mathrm{cm}^{-2}$ \\
\hline $\begin{array}{c}\text { This work } \\
\text { cycles }\end{array}$ & $0.074 \%$ up to 300 & $0.25 \mathrm{C}$ & $9.0 \mathrm{mg} \mathrm{cm}^{-2}$ \\
\hline cycles & & \\
\hline
\end{tabular}


TOC Graphic

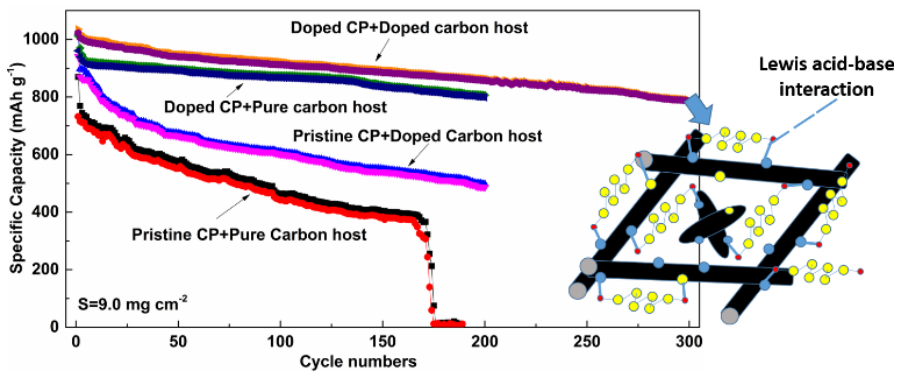

